\title{
Vaginal hysterectomy in Primary Health Center, Darchula: A remote area of rural Nepal
}

\author{
Padam R Pant, Bhoj R Joshi*, Karbir N Yogi', Shyam S Mishra**, Bhim S Tinkari** \\ Dept of Obs/GynTUTH, *Dept of Anesthesia Nepalgani Medical Col., 'Dept of Medicine TUTH, \\ **Regional Health Director for Western Region, ***Deputy Director Farwestern Region of Heath
}

\begin{abstract}
Aim: To make situational analysis of getting organized with vaginal hysterectomy and pelvic floor repair for uterine prolapse in Primary Health Center in remote area.

Method: This is a prospective descriptive study conducted in a three bedded Primary Health Center 'Gokuleswar' of Darchula district in far western region of Nepal. The vaginal hysterectomy camp was funded by Ministry of health. Women with second and third degree prolapse or complete procidentia were screened for operation. Patient were investigated for urine routine and microscopic examination, blood grouping, haemoglobin, total and differential count, bleeding time clotting time, blood sugar random, HIV, HBsAg.

Result: 72 patients were operated. Majority of the patients were 40-50 years of age. Two patients (2.7\%) were below 30 years of age. Parity ranged from 2-13. Among the operated patients, $49(68 \%)$ had complete procidentia. More than half of the patient 37(51.38\%) had prolonged bleeding time, one patient (1.38\%) needed laprotomy for uncontrolled bleeding and required right sided internal artery ligation for haemostasis.

Conclusion: Providing surgical service in rural setting at their own door step to the Nepalese women who have no time to travel to different hospital at their own cost is divine. Such an out reach programme is a major health benefit.
\end{abstract}

Key words: Uterovaginal prolapse, vaginal hysterectomy, rural gynecological problem.

\section{Introduction}

Utero-vaginal prolapse is one of the common gynaecological problems of the women of rural Nepal as the women return to heavy work early after, unsupervised home delivery, short spacing in between the births, multi parity. However in Manang general health camp there was not even a single case of uterovaginal prolapse. ${ }^{1}$

Gokuleswar Primary Health Center (PHC) is at the bank of Chameliya River in Darchula district, a remote district of far western Nepal. This is the only PHC in this area and is equipped with three beds. In this health centre there is a health assistant with supportive staffs. District hospital is very far from this area and takes about 2 days to reach there walking on foot as there are no other methods to travel. The district itself does not have any surgical facilities for such major surgeries. So, for such major surgeries the patients have to go to
India which costs at least 30,000 Indian rupees and is beyond their capacity.

\section{Methods}

This is a prospective, descriptive study done in Gokuleswar PHC in Darchula district of far western region of Nepal from 10th- 17th Baishakh 2064.

A 7 day gynaecological surgical camp was organized by the ministry of health, focusing the uterovaginal prolapse. Excluding women with first degree uterovaginal prolapse; all others with second - third degree uterovaginal prolapse to complete procidentia were screened for vaginal hysterectomy and pelvic floor repair. Patient who were cancelled for operation due to systemic disorders, active genital infection, suspected malignancies and those who had not completed family were excluded from the study. Before operation all the women with uterovaginal prolapse were screened by 
operating surgeon, and anaesthetist and investigated for blood grouping, haemoglobin, bleeding time, clotting time, Random blood sugar, HBsAg, HIV, urine routine and microscopic examination but there was no facility of X-ray so suspected cases were seen by physician. All the vaginal hysterectomies were done under spinal anaesthesia.

\section{Results}

The age of the patients ranged from 26-75 years. Majority of them were between 40-50 years of age. Parity ranged from 2-13. About $68 \%$ (49) patients had complete procidentia, $24 \%(17)$ had third degree and 8 $\%$ ( 6) had second degree uterovaginal prolapse. Two of the patients with second degree uterovaginal prolapse also had myoma of the uterus.

Most of the patients $56(77.7 \%)$ had the history of early return to work after delivery (within 15 days). All patients except one had unsupervised vaginal delivery. More than $50 \%$ had gap of less than two years in between two pregnancies. $11(15.27 \%)$ of these operated patients had history of conception in lactational amenorrhea within a year in their second pregnancy. Twelve $(17 \%)$ patients were chronic smokers.

Women with longstanding prolapse for 46 years were also operated in the camp.

All the vaginal hysterectomy with pelvic floor repair operations was done under spinal anaesthesia. The difficulty encountered in this camp was that, many of the patients 37 (51.38\%) had bleeding time 4.5-5 minutes. Problems of haemostasis were faced during operation in many women. This was counteracted by infiltration of local adrenaline injection and tranexamic acid.

One of the patients with second degree utero-vaginal prolapse with uterine myoma of about 12-14 weeks gestational size had been cancelled during screening. She being known to some health center staff was included among the other prolapse cases without surgeon's knowledge and already had been anaesthesized. Vaginal hysterectomy was done by bisection of the uterus. ${ }^{2}$ There was uncontrolled bleeding and the bleeder could not be identified vaginally so laprotomy was done. Even after laprotomy the active bleeder could not be identified and the right sided internal iliac artery ligation was done under general anaesthesia.

Two patients were under 30 years of age ideally Fothergill's operation would be the best option for these two ladies but both of them had complete procidentia. One of them already had 4 children and the other had 3 children. The patient and party were counseled for above mentioned operation but the patient requested for hysterectomy, so, vaginal hysterectomy and pelvic floor repair was done on these two young ladies.

Except haemostatic problems there were no other complications. Three patients required 2 pints of blood transfusion each, as they had haemoglobin of $8 \mathrm{gm} \%$ or less. Post operative bladder catheterization was done for 48 hours. All the patients had uneventful early post operative period. Patients were discharged on the fourth post operative day after the return of normal bladder and bowel functions. None of the patients required recatheterization. ${ }^{4}$

\section{Discussion}

Going to the community for health reason is not a new thing in Nepal. Reaching to the community has been exercised for many years. Some of the camps in the yester years even had Royal presence. In these camps obstetric emergencies like obstructed labour and surgical emergencies like ruptured ectopic were operated.

Now and then, mainly in time of suitable weather, different governmental and non governmental organization have been organizing camps in remote areas, which are basically out of reach. Doctors and staff have been walking miles for days together to help the needy women. In these rural camps many cases of pelvic organ prolapse were seen. ${ }^{3}$ But they were only provided by vaginal ring pessary before. Because of abundant number of cases, the inception of the surgical camps at the local rural setting was modeled not very long ago. Doctors from Institute of Medicine have organized such camps now and then and Gynecologist have operated on women with prolapse in different areas of Nepal. ${ }^{5}$ But this time, it has been, indeed a pride to be a part to of a prestigious Governmental Programme.

One may have some reservation for operating uterovaginal prolapse in less equipped hospital as these are major operation. But it is very difficult to get the women coming from this area at a district hospital, ideally which is better place for surgery. In consideration of many obstacles mainly due to mountains all around as a geographical set back, it has not been easy to bring these women who prefer not to travel long leaving home and cattle their prized possessions, to a distantly situated or well equipped facility in the district. Hence site selection is based in the area where there are maximum number of uterovaginal prolapse cases and a furthest point, so that many women can be covered within same financial reach.

But being a surgeon of a surgical camp in rural Primary Health Center really needs perception, patience, capability to be instantaneously decisive and competent to deal with whatever complications that arises at that same spot, since the next referral facilities 
are very far away or nonexistent. It is a challenging experience for all those who can tactfully manage all the complications immediately, however life threatening they might be. In this camp there was one life threatening complication of intraperitoneal bleeding, which was dealt without any hue and cry but with great responsibility shared by the surgical team as right internal iliac artery ligation saved her life. Had she needed referral for DIC or there was no way out, as there are no well equipped referral centers with intensive care facility in the whole far western region. To avoid these life threatening complications, surgeon must screen the cases themselves examining every detail systematically, ensure thoroughly that there are proper investigation before taking up for operation. A case that needs extra time must be kept in less busy day. A difficult case should not be rushed for surgery without consulting Physician/Anesthetist. This woman in concern did enter from back door despite having been deferred for operation in the context of fibroid and bleeding prolonged time. However, she could still have had abdominal procedure safely or returned without surgery, as earlier said anything could have happened. She is alive today, only because of quick decision to open or surgical expertise in moving with the necessary steps immediately.

Myoma sized 12-17weeks gestation weighing 280-570 gm has been successfully bisected, enucleated or morcellated and removed vaginally in 22/25 hysterectomy with one severe intraoperative hemorrhage. ${ }^{6}$

Hemorrhagic complications have occurred following vaginal hysterectomy in our own hospital, none needing internal iliac ligation in our hospital. ${ }^{7,8}$ Whereas hypogastic artery ligation have been helpful for intractable hemorrhage at pelvic (gynecological) surgery in $41 / 80$ cases in one of the study. ${ }^{9}$

All the patient were followed by the operating surgeons at least for two days. For this last two days of the camp were reserved for post operative care of the women. Patients were followed by medical officer for additional five days. No other life threatening post operative infections were recorded. Seventy-one vaginal hysterectomies for non prolapse were performed as 24-hour day case where 65 women were discharged home within 24 hours $(91.5 \%)$ and intraoperative complication rate of $1.4 \% .^{10}$

\section{Conclusion}

Vaginal Hysterectomy Surgical Camps for uterovaginal prolapse in rural set up is very helpful for rural Nepalese women and equally stands true for Darchula with successful surgical coverage of 72 cases in span of 5 days with a noteworthy management of a life threatening complication. Such an outreach camp is divine for women living with prolapse related prolonged morbidity for almost half century.

Aknowledgement: Would like to thank Dibyaswari Nepali, Srijana Chhetri, Pratibha Sharma, Durga Bhandari, Dela Pun, Mahima Aitwal who have been of utmost help in the preparation of this manuscript.

\section{References}

1. Pant PR, Singh KP, Sharma NR, Giri P, Shrestha $\mathrm{K}$, Kuwar K. None with uterovaginal prolapse in Gynaecological camp. Gynaecology and Obstetric annual health letter2003.9:59-60.

2. Tuladhar H. An overview of reproductive health of women in Bajhang districts. Nepal Med Coll J. 2005 Dec; 7(2):107-11.

3. Gurung G. Uterovaginal prolapses in association with ovarian tumours and myoma. Surgical approaches. Gyn and Obs Annual health letter 2003; 9: 62 61-???

4. Pant PR. An effective Short duration postoperative catheterization after vaginal hysterectomy and pelvic floor repair. Journal Institute of Medicine.2006.28:33-35.

5. Ashma Rana. Reducing morbidity from uterovagnal prolapse in Neplease women through surgical camp: an ambitious approach. Nepal Obstetrics and Gynaecology 2006.1:1-3

6. Lu Y, Zhang S, Liu X. Clinical study on transvaginal hysterectomy for moderate enlarged uterus Zhonghua Fu Chan Ke Za Zhi. 1999 Aug; 34(8):453-5

7. Rana A, Gurung G, Pradhan N. Prolapse and problem. JSSN 2001; 4(1).32

8. Rana A Singh KP, Jha R, Shah R, Baral Josie. Haemorrage following vaginal hysterectomy. A case report. Follicle 1997/1998; 2(1): 14-17.

9. Papp Z, Tóth-Pál E, Papp C, Sziller I, Silhavy M, Gávai M, Hupuczi P. Bilateral hypogastric artery ligation for control of pelvic hemorrhage, reduction of blood flow and preservation of reproductive potential. Experience with 117 cases. Orv Hetil 2005 Jun 12; 146(24):1279-85.

10. Penketh R, Griffiths A, Chawathe S. A prospective observational study of the safety and acceptability of vaginal hysterectomy performed in a 24-hour day case surgery setting. BJOG. 2007 Apr; 114(4):430-6. 